\title{
INTOXICACIÓN POR ORGANOFOSFORADOS
}

\author{
Daniel G. Fernández A. MD..$^{*}$, Liliana C. Mancipe G. Md. ${ }^{2}$ ү Diana C. Fernández A. MD. ${ }^{3}$ \\ ${ }^{1}$ Médico Internista, Residente de Reumatología Universidad Militar Nueva Granada. \\ ${ }^{2}$ Médica Fisiatra Hospital Militar Central. 3 Médica Interna Hospital San Rafael de Tunja, Universidad \\ Pedagógica y Tecnológica de Colombia UPTC
}

\begin{abstract}
Resumen
Los compuestos organofosforados son un grupo de sustancias orgánicas derivadas de la estructura química del fósforo y tienen un gran número de aplicaciones y utilidades. Han sido utilizados como aditivos del petróleo, disolventes, en las industrias de colorantes, barnices, cuero artificial, aislantes eléctricos, impermeabilizantes, ablandadores de plásticos, fungicidas, insecticidas entre otros. Dado su amplia distribución y uso en diferentes industrias y en la agricultura, es muy frecuente que se presenten intoxicaciones accidentales por estos compuestos; además, como son sustancias que están al alcance de las personas, han sido empleadas como tóxicos en suicidios. El cuadro de intoxicación genera un síndrome clínico característico, con síntomas colinérgicos secundarios a la estimulación de los receptores de acetilcolina. El manejo médico de estos pacientes puede significar la diferencia entre la vida y la muerte, por lo que es importante que todo el personal de salud en los servicios de urgencias esté capacitado para reconocer el cuadro de intoxicación y manejarlo rápidamente en forma adecuada.
\end{abstract}

Palabras clave: organofosforados, intoxicación, acetilcolina, acetilcolinesterasa

\section{ORGANOPHOSPHORUS POISONING}

\begin{abstract}
Summary
Organophosphorus compounds are a group of organic substances derived from the chemical structure of phosphorus. They have a large number of applications and utilities. They are used as oil additives, solvents, in the industry of dyes, varnishes, artificial leather, electrical insulation, waterproofing, plastic softeners, fungicides and others. Given its wide distribution and use in different industries and trades, organophosphorus compounds can be taken accidentally causing intoxication and can be used with the intention to commit suicide. The intoxication with organophosphorus compounds produces a characteristic clinical syndrome with cholinergic symptoms after stimulation of acetylcholine receptors. The medical management of these patients could make the difference between life and death, hence the physician and all health personnel in the emergency department should be able to recognize and manage poisoning symptomatology properly.
\end{abstract}

Keywords: organophosphorus, intoxication, acetylcholine, acetylcholinesterase

* Correspondencia: Daniel Fernández danielfernandezmd@gmail.com. Dirección postal: Tr. 3 No.49-00. Facultad de Medicina, Universidad Militar Nueva granada, Bogotá, Colombia.

Recibido: Marzo 10 de 2010 Aceptado: Junio 15 de 2010. 


\title{
INTOXICAÇÃO POR ORGANOFOSFORADO
}

\begin{abstract}
Resumo
Os compostos organofosforados são um grupo de substâncias orgânicas derivadas da estrutura química de fósforo e tem um grande número de aplicações e usos. Têm sido utilizados como aditivos para óleos, solventes, indústrias de tintas, vernizes, couro artificial, isolação elétrica, impermeabilização, amaciadores de plástico, fungicidas, inseticidas, entre outros. Dada a sua ampla distribuição e uso em diferentes indústrias e na agricultura, é muito comum ter intoxicações acidentais por esses compostos, além disso, substâncias que estão disponíveis para os indivíduos, têm sido usadas como substância tóxica em suicídios. O quadro de intoxicação produz uma síndrome clínica característica, com sintomas colinérgica secundários à estimulação dos receptores de acetilcolina. A conduta médica destes pacientes pode significar a diferença entre a vida ea morte, por isso é importante que todo o pessoal de saúde nos serviços de emergência seja treinado para reconhecer a figura de intoxicação $e$ rapidamente tratar adequadamente.
\end{abstract}

Palavras-chave: organofosforado, intoxicação, acetilcolina, acetilcolinesterase

\section{Introducción}

Los compuestos organofosforados son ésteres del ácido fosfórico y de sus derivados, que comparten como característica farmacológica la acción de inhibir enzimas con actividad esterásica, más específicamente de la acetilcolinesterasa en las terminaciones nerviosas, lo que genera una acumulación de acetilcolina y como consecuencia se altera el funcionamiento del impulso nervioso. Estos compuestos son liposolubles y volátiles, características que facilitan su absorción; su toxicidad es variable (I, II, III), y los efectos farmacológicos varían de acuerdo al grado de toxicidad y vía de entrada en el organismo $(1,2)$. El cuadro de intoxicación por organofosforados genera un espectro de signos y síntomas característico, conocido como síndrome colinérgico que se presenta como consecuencia de la excesiva estimulación de los receptores de acetilcolina, y que se caracteriza principalmente por cambios en el estado de conciencia, debilidad muscular y excesiva actividad secretora. El manejo oportuno de este síndrome es clave para evitar complicaciones graves secundarias a la intoxicación e incluso el compromiso de la vida del paciente (3).

Dado que en Colombia los plaguicidas organofosforados, un grupo de compuestos altamente tóxicos, son muy utilizados especialmente en el campo de la agricultura, es muy importante conocer cuáles son los productos más utilizados y cuáles son los niveles de toxicidad (Tabla 1). Los más usados pertenecen los grupos fosfatos, los fosfanatos y sus derivados azufrados.

\section{Plaguicidas}

La FAO (Food and Agriculture Organization of the United Nations) define a un plaguicida como "una sustancia o mezcla de substancias destinadas a prevenir, destruir o controlar cualquier plaga, incluyendo vectores de enfermedad humana o animal, especies indeseadas de plantas o animales capaces de causar daños o interferir de cualquier otra forma con la producción, procesamiento, almacenamiento, transporte o mercado de los alimentos, otros productos agrícolas, madera y sus derivados o alimentos animales, o que pueden ser administrados a los animales para el control de insectos, arácnidos u otras plagas en sus organismos" $(4,5)$.

En Colombia, los plaguicidas son utilizados ampliamente en diferentes campos, principalmente en la agricultura para mejorar la calidad y la cantidad de los alimentos, a nivel doméstico para eliminar insectos y a nivel de la salud pública, para el control de vectores transmisores de enfermedades. Entre los efectos adversos que se pueden citar están la contaminación ambiental y la toxicidad para los humanos.

\section{Clasificación de los Plaguicidas}

Las intoxicaciones por insecticidas, entre ellos los organofosforados, hacen parte de la lista de eventos de notificación obligatoria a nivel nacional. Estas sustancias se pueden clasificar según su toxicidad, su naturaleza química o su función $(6,7)$. 
TABLA 1. Organofosforados de mayor uso en Colombia.

\begin{tabular}{cll}
\hline $\begin{array}{c}\text { Categoría } \\
\text { Toxicológica }\end{array}$ & \multicolumn{1}{c}{$\begin{array}{c}\text { Nombre } \\
\text { genérico }\end{array}$} & \multicolumn{1}{c}{$\begin{array}{c}\text { Nombre } \\
\text { comercial }\end{array}$} \\
\hline I & Diclorvos & Diclorvos, Vapona \\
I & Mevinphos & Mevinfos \\
I & Monocrotofos & Monocrotofos 600 SL \\
I & Metilparation & Metilparation, Folidol \\
I & Paration & Parawet, Folidol \\
I & Metamidofos & Tamarón, Monitor \\
II & Coumafos & Asuntol, CoRal \\
II & Diazinon & Basidon \\
II & Fenthion & Lebaycid 500 SC \\
II & Profenofos & Curacron, Tambo \\
III & Clorpirifos & Arriero 2,5, Lorsban \\
III & Malathion & Malathion, Aucuafin \\
\hline
\end{tabular}

Modificado de Thomson PLM S.A. Diccionario Especialidades Agroquímicas. Edición 16. Bogotá: La Entidad, 2006. De: Ministerio de la Protección Social. Guía de Atención Integral en Salud Ocupacional Basada en la Evidencia para Trabajadores Expuestos a Plaguicidas Inhibidores de la Colinesterasa (organofosforados y Carbamatos) GATISO PIC 2007.

Clasificación según toxicidad: para su clasificación se tiene en cuenta la dosis letal 50 (DL50), la cual se define como la cantidad de una sustancia que al ser suministrada a animales de experimentación mata al $50 \%$ de esa población (3). En Colombia, el Ministerio de la Protección Social mediante el decreto 1843 de 1991, reglamentó todo lo relacionado con estos compuestos entre ellos el grado de toxicidad (Tabla 2).

A nivel internacional está establecido que los envases y empaques de plaguicidas deben llevar una banda del color que identifique la categoría toxicológica del contenido así: Categoría I = roja, II = amarilla, III = azul y IV = verde (8).

Clasificación según su naturaleza química: la clasificación de los plaguicidas según su origen químico y sus características están en la Tabla 3 y pueden ser de origen natural, hasta totalmente sintéticos.

Clasificación según su función: pueden ser insecticidas, fungicidas, herbicidas y rodenticidas (4).
TABLA 2. Clasificación de plaguicidas según categoría toxicológica.

\begin{tabular}{clc}
\hline Categoría & \multicolumn{1}{c}{ Definición } & $\begin{array}{c}\text { Dosis letal } 50 \text { (oral } \\
\text { aguda en ratas) }\end{array}$ \\
\hline I & $\begin{array}{l}\text { Extremadamente } \\
\text { tóxicos }\end{array}$ & $0-5 \mathrm{mg} / \mathrm{kg}$ \\
II & Altamente tóxicos & $5-50 \mathrm{mg} / \mathrm{kg}$ \\
III & Medianamente tóxicos & $50-500 \mathrm{mg} / \mathrm{kg}$ \\
IV & Ligeramente tóxicos & Mayor de $500 \mathrm{mg} / \mathrm{kg}$ \\
\hline
\end{tabular}

Modificado de Instituto Nacional de Salud Colombia - Subdirección de Vigilancia y Control. Intoxicación aguda por plaguicidas. Primer semestre de 2007.

\section{Insecticidas:}

- Organoclorados: endrín, aldrín, DDT, lindano, toxafeno

- Organofosforados: paratión, clorpyrifos, diazinon, diclorvos, malation, dimetoato

- Carbamatos: aldicarb, carbofuran, propoxur, carbaril.

- Piretrinas y piretroides: resmetrina, bioresmetrina, aletrina, decametrina, permetrina.

- Otros: ivermectina.

Fungicidas:

- Sales de cobre: oxicloruro de cobre y sulfato de cobre.

- Derivados de la ftalimida: captafol

- Dinitrofenoles: dinitro-orto-cresol

- Dithiocarbamatos: maneb, zineb, mancozeb.

TABLA 3. Clasificación de plaguicidas según naturaleza química

\begin{tabular}{ll}
\hline \multicolumn{1}{c}{ Tipo } & \multicolumn{1}{c}{ Características } \\
\hline Inorgánicos & $\begin{array}{l}\text { Fabricados a partir de metales como } \\
\text { cobre, plomo, arsénico }\end{array}$ \\
Vegetales & $\begin{array}{l}\text { Extraídos de diversas partes de vegetales, } \\
\text { como las piretrinas }\end{array}$ \\
Organosintéticos & $\begin{array}{l}\text { Sintetizados por el hombre en el labora- } \\
\text { torio (organoclorados, organofosforados, } \\
\text { carbamatos) }\end{array}$ \\
$\begin{array}{l}\text { Microorganis- } \\
\text { mos vivos }\end{array}$ & $\begin{array}{l}\text { Virus, bacterias y hongos utilizados en el } \\
\text { control biológico de plagas }\end{array}$ \\
\hline
\end{tabular}

Modificado de: Instituto Nacional de Salud Colombia - Subdirección de Vigilancia y Control. Intoxicación aguda por plaguicidas. Primer semestre de 2007. 


\section{Herbicidas:}

- Bipiridilos: paraquat, diquat

- Glifosato

\section{Rodenticidas:}

- Inorgánicos: sulfato de tálio, anhídrido arsenioso, fosfuro de aluminio, fosfuro de zinc.

- Orgánicos: anticoagulantes: cumarinas (Warfarina).

\section{Epidemiología}

Los reportes de la organización mundial de la salud (OMS) muestran que anualmente a nivel mundial, hay aproximadamente un millón de intoxicaciones accidentales y dos millones de intoxicaciones provocadas (suicidios) con insecticidas, de las cuales aproximadamente 200.000 terminan en la muerte (5).

A pesar de que en Colombia las intoxicaciones causadas por plaguicidas representan un importante problema de salud pública debido a los múltiples usos de estos en los diferentes campos, especialmente a nivel agrícolas, las estadísticas sobre las intoxicaciones por organofosforados son muy bajas, debido principalmente a un marcado subregistro en la notificación de las intoxicaciones ocasionadas no sólo por estos compuestos, sino también por las ocasionadas con otras sustancias (6). En las últimas décadas se han presentado tres eventos masivos de intoxicación por organofosforados: En el año 1967 en Chiquinquirá, donde cerca de 500 personas se intoxicaron con metilparatión, de las cuales murieron 63; en 1970 en Puerto López, cerca de 190 personas se intoxicaron con un organofosforado no determinado, causando la muerte a siete de ellas; y en Pasto en 1977, 300 personas resultaron intoxicadas con paratión, causando la muerte a 15 de ellas (6).

Según un estudio realizado en diferentes países de Centroamérica, se estima que $3 \%$ de los trabajadores agrícolas que están expuestos a los plaguicidas sufren cada año una intoxicación aguda. La tasa de incidencia para estas intoxicaciones en la región Centroamericana ha mostrado un progresivo aumento del riesgo, pasando de tasas de 6,3 por cien mil habitantes en 1992 a 19,5 en el año 2000. Igualmente las tasas de mortalidad presentan una tendencia al ascenso, pasando de un riesgo de muerte de 0,3 por 100.000 habitantes en 1992 a 2,10 en el año 2000 (8).
De acuerdo con los datos obtenidos a través del Sistema de Vigilancia Epidemiológica en Centroamérica, los doce plaguicidas que están relacionados con el mayor número de intoxicaciones agudas son: paraquat, fosfato de aluminio, metil-paratión, metamidofos, monocrotofós, clorpirofós, terbufós, etoprofós, endosulfan, carbofurán, metomil y aldicarb (8). Estudios epidemiológicos realizados a nivel mundial han encontrado relación entre la exposición pre y postnatal a pesticidas con el desarrollo de diferentes tipos de cáncer en niños, muerte fetal, retardo del crecimiento intrauterino, nacimientos pretétminos y defectos al nacimiento (9).

\section{Fisiopatología}

Absorción de los organofosforados: pueden penetrar al organismo por inhalación, ingestión y a través de la piel intacta, debido a su alta liposolubilidad, característica que hace que pasen las barreras biológicas más fácil, y por su volatilidad facilitando su inhalación $(9,10)$.

Metabolismo: una vez absorbidos y distribuidos en el organismo, los plaguicidas organofosforados son metabolizados de acuerdo con la familia a la que pertenezca el compuesto, prinipalmente en el hígado. Una vez que entran en el organismo poseen una vida media corta en el plasma y un elevado volumen de distribución en los tejidos (9). Los organofosforados son metabolizados por una serie de enzimas (esterasas, enzimas microsomales, transferasas) fundamentalmente en el hígado, sufriendo una serie de transformaciones químicas. Estas transformaciones tienden a aumentar la hidrosolubilidad del plaguicida y por consiguiente facilitan su excreción, la cual se da a nivel renal (11).

Mecanismo de acción: los organofosforados desarrollan su toxicidad a través de la fosforilación de la enzima acetilcolinesterasa en las terminaciones nerviosas. Los pesticidas organofosforados reaccionan con la zona esterásica de la enzima colinesterasa formando una unión estable que si no se rompe mediante el tratamiento, se hace irreversible, quedando la enzima inhabilitada para su función normal. La pérdida de la función enzimática permite la acumulación de acetilcolina en las uniones colinérgicas neuroefectoras (efectos muscarínicos), en las uniones mioneurales del esqueleto y los ganglios autónomos (efectos nicotínicos) y en el sistema nervioso central (SNC) $(11,12)$. 
La acetilcolina es un neurotransmisor que interactúa con dos tipos de receptores postsinápticos (nicotínicos y muscarínicos), y es responsable de la transmisión fisiológica del impulso nervioso de: a. Las fibras colinérgicas postganglionares simpáticas y parasimpáticas a las células efectoras (receptores muscarínicos). b. Las neuronas preganglionares a las postganglionares en los sistemas parasimpáticos y simpáticos (receptores nicotínicos). c. Los nervios motores al músculo esquelético (receptores nicotínicos). d. Algunas terminaciones nerviosas en SNC (13). Una vez es liberada y ha interactuado con su receptor, la acetilcolina es destruida mediante la acción de la enzima acetilcolinesterasa, la cual reacciona con el neurotransmisor hidrolizándolo y produciendo colina y ácido acético, que entran al pool metabólico presináptico para ser utilizados nuevamente.

\section{Manifestaciones clínicas}

Las intoxicaciones con compuestos organofosforados pueden generar tres cuadros clínicos: la intoxicación aguda, el síndrome intermedio y una neurotoxicidad tardía. El cuadro de intoxicación aguda genera un conjunto de signos y síntomas denominados síndrome colinérgico el cual se presenta como consecuencia de la excesiva estimulación de los receptores de acetilcolina, y que se caracteriza principalmente por cambios en el estado de conciencia, debilidad muscular y excesiva actividad secretora. La aparición de este cuadro varía entre pocos minutos hasta doce horas posterior al contacto con el tóxico, dependiendo de la edad del paciente, la cantidad ingerida y la toxicidad intrínseca del organofosforado (14); en los niños los efectos nicotínicos se observan con mayor frecuencia que en los adultos (15).

En la tabla 4 se resumen los cuadros clínicos de la intoxicación aguda: efectos muscarínicos, nicotínicos y en el sistema nervioso central.

El síndrome Intermedio aparece posterior a los efectos agudos, es decir 24 - 48 horas después de la exposición, pero antes que la neuropatía retardada; se caracteriza por debilidad de los músculos proximales de las extremidades, flexores del cuello, lengua, faringe y músculos respiratorios, con compromiso de la función respiratoria, disminución o ausencia de los reflejos miotendinosos y compromiso de pares craneales (principalmente el sexto). Su incidencia es de $57,1 \%$ (14). Algunos estudios han mostrado que
TABLA 4. Características del Sindrome Colinérgico

\begin{tabular}{|c|c|c|}
\hline $\begin{array}{c}\text { Efectos } \\
\text { muscarínicos }\end{array}$ & $\begin{array}{c}\text { Efectos } \\
\text { nicotínicos }\end{array}$ & Efectos snc \\
\hline $\begin{array}{l}\text { Visión borrosa, } \\
\text { miosis, hiperemia } \\
\text { conjuntival, rinorrea, } \\
\text { broncorrea, sialorrea, } \\
\text { broncoespasmo, } \\
\text { cianosis, diaforesis, } \\
\text { náuseas, vómito, } \\
\text { diarrea, cólico } \\
\text { abdominal, } \\
\text { incontinencia de } \\
\text { esfínteres, bradicardia }\end{array}$ & $\begin{array}{l}\text { Vasoconstricción } \\
\text { periférica, } \\
\text { Calambres, } \\
\text { mialgias, } \\
\text { fasciculaciones, } \\
\text { debilidad, } \\
\text { parálisis flácida, } \\
\text { hiperglicemia }\end{array}$ & $\begin{array}{l}\text { Cefalea, } \\
\text { ansiedad, } \\
\text { confusión, } \\
\text { irritabilidad, } \\
\text { alteración } \\
\text { del estado de } \\
\text { conciencia, } \\
\text { ataxia, depresión } \\
\text { respiratoria, } \\
\text { convulsiones }\end{array}$ \\
\hline
\end{tabular}

el síndrome intermedio sólo ocurre en pacientes con inhibición prolongada de la acetilcolinesterasa y que la presencia del síndrome no depende del tipo de agente tóxico involucrado (16). En el país se ha observado que los agentes más asociados a la aparición de este síndrome son el fentión, dimetoato, monocrotofos y metamidofos $(6,7)$.

La neuropatía retardada se presenta principalmente con los compuestos que contienen flúor; puede niciarse entre una a cuatro semanas después de la exposición aguda al tóxico. Los posibles mecanismos fisiopatológicos para su aparición son la inhibición de una enzima axonal conocida como esterasa neurotóxica (NTE) del sistema nervioso y el incremento del $\mathrm{Ca} 2+$ intracelular por alteración de la enzima calcio-calmomodulinaquinasa II, produciendo degenración axonal. Se trata de una polineuropatía predominantemente motora, de tipo flácido, pero también con manifestaciones de tipo sensorial, que afecta a los músculos dístales de las extremidades que se manifiesta con debilidad ascendente pero de predominio distal, ataxia, hipotrofia muscular, hiporreflexia en miembros inferiores, calambres, parestesias, dolor neuropático, e hipoestesia; su recuperación puede ser total o parcial entre 6-12 meses con una adecuada rehabilitación. Dentro de los organofosforados que más se han asociado se encuentran el leptofox, mipafox, clorpirifox, triclorfón, fentión y diazinón.

Se ha encontrado evidencia sobre la asociación entre exposición crónica a organofosforados y la aparición de síntomas extrapiramidales y psiquiátricos como psicosis, ansiedad, depresión, alucinaciones y agresividad (17). En niños se ha demostrado que la intoxicación por organofosforados puede producir trastornos del 
desarrollo psicomotor, con alteración de las pruebas neuroconductuales (18).

\section{Diagnóstico}

El diagnóstico inicial se realiza con la historia clínica, mediante la sospecha o certeza de la exposición al tóxico, la vía de absorción y un cuadro clínico compatible. La confirmación diagnóstica debe realizarse idealmente mediante la medición de la actividad de la colinesterasa. Los niveles de colinesterasa varían de un individuo a otro, por tal razón se recomienda medir los niveles de esta enzima a las personas que van a estar en contacto con los compuestos organofosforados, antes de que se inicie la exposición a estas sustancias (19).

Los plaguicidas organofosforados disminuyen la actividad tanto de la colinesterasa plasmática como de la eritrocitaria; la primera se recupera de forma más rápida (entre 15 a 30 días) y la eritrocitaria entre 0 a 90 días aproximadamente (20). Es importante tomar en cuenta que la actividad de la colinesterasa plasmática también puede estar disminuida en pacientes con hepatitis crónica, cirrosis, otras enfermedades hepáticas y en consumidores de drogas (21).

Existen cuatro tipos de métodos para detección de la actividad de la colinesterasa: el electrométrico, el colorimétrico, el cinético y el tintométrico (21). Idealmente recomiendan medir la actividad de la colinesterasa eritrocitaria por el método electrométrico de Michel. Este método mide el ácido producido por la acción de la acetilcolinesterasa sobre la acetilcolina en términos de cambio de $\mathrm{pH}$ en una solución tampón estándar en una hora. Los valores normales de colinesterasa en sangre total, por este método se han determinado entre 91-64 opH/hora (14,21). Varios estudios se han diseñado para tratar de determinar la relación entre los niveles séricos de colinesterasa y la severidad de la intoxicación por organofosforados, concluyéndose que estos niveles no tienen ningún valor pronóstico (22).

La necesidad de asistencia ventilatoria es un indicador de severidad de la intoxicación; sin embargo, no se pudo establecer su relación con los niveles séricos de colinesterasa, al igual que la de los requerimientos de atropina (22). Los valores que se han establecido para determinar la severidad de la intoxicación por el método de laboratorio de Mitchell son:
- Actividad de la enzima mayor al $75 \%$ : Normal

- Actividad de la enzima entre 50\% - 75\%: intoxicación leve

- Actividad de la enzima entre $25-50 \%$ : intoxicación moderada

- Actividad de la enzima menor al 25\%: intoxicación grave (16,23-25).

Para la identificación de complicaciones se deben realizar otros examenes tales como el hemograma y la sedimentación globular para observar si hay leucocitosis con neutrofilia; el ionograma completo que incluya magnesio ya que se puede presentar hiponatremia, hipomagnesemia e hipocalemia; medición del pH y gases arteriales debido a que se puede encontrar acidosis metabólica; BUN y creatinina debido a la posibilidad de desarrollar falla renal; AST, ALT, Bilirrubinas y FA por el riesgo de hepatotoxicidad; amilasas séricas ya que se han descrito casos de pancreatitis hemorrágica; $\mathrm{Rx}$ de tórax para descartar la presencia de neumonitis química y/o broncoaspiración y un electrocardiograma $(15,26)$.

\section{Tratamiento}

\section{Evaluación inicial y manejo de urgencias}

El tratamiento inicial debe enfocarse a asegurar la permeabilidad de la vía aérea y la adecuada función cardiovascular mediante el algoritmo del ABCDE $(27,28)$. En estos pacientes es esencial una adecuada aspiración de secreciones. Se debe realizar una descontaminación adecuada según la vía de entrada del tóxico, ya sea con baño corporal, lavado del cabello, retiro de ropa, uso de carbón activado a dosis convencional y catártico (29-31).

En los casos de intoxicación por vía cutánea el paciente debe ser lavado con abundante agua y jabón, recordando que todo el personal médico y de enfermería debe tener las precauciones necesarias para evitar convertirse en otra víctima de intoxicación (32). En cuanto al lavado gástrico, este no debe retardar la administración del tratamiento específico; es recomendado solamente en pacientes en quienes se sospeche la presencia de restos tóxicos en el estómago (ingestión $<2$ horas) o en pacientes con intubación orotraqueal para minimizar el riesgo de broncoaspiración (33). 


\section{Manejo Específico}

Atropina: se utiliza para el manejo de los efectos muscarínicos por competición de receptores con la acetilcolina. La atropinización debe iniciarse una vez esté asegurada la vía aérea. La dosis inicial es de 1 a $5 \mathrm{mg}$ IV (niños 0,02 a 0,05 mg/kg), evaluando la respuesta a intervalos de cinco a diez minutos, buscando como guía terapéutica la aparición de signos de atropinización como aumento de la frecuencia cardiaca, disminución de secreciones respiratorias, midriasis, resequedad o normalidad de piel y mucosas, y vigilando la aparición de angina, excitación de origen central (delirio, alucinaciones) y retención urinaria. En pacientes con intoxicaciones severas, posteriormente se puede requerir un goteo contínuo de atropina entre 0,01 y $0,08 \mathrm{mg} / \mathrm{kg} / \mathrm{h}$ que deberá retirarse gradualmente para evitar bradiarritmias (14).

Oximas: actúan mediante la reactivación de la colinesterasa eliminando su grupo fosfato. Idealmente deben ser empleadas en las primeras seis horas para evitar la unión irreversible entre el tóxico y la colinesterasa $(34,35)$. Aunque existen diferentes oximas y protocolos de administración, la más empleada es la pralidoxima (amp 1g/20 ml) a una dosis de 25 a $50 \mathrm{mg} / \mathrm{kg}$ ( 1 a $2 \mathrm{~g}$ ), diluido en 100 cc de solución salina $0,9 \%$ para pasar en 30 minutos, seguido de una infusión continua a $8 \mathrm{mg} /$ $\mathrm{kg} / \mathrm{h}$ por 24 horas $(14,36)$. Otra alternativa es la administración de 1 a 2 g por vía IV o IM cada cuatro horas.

Varios estudios han comparado la administración de pralidoxima mediante infusión contínua versus bolos cada cuatro horas, encontrando que la infusión contínua a $1 \mathrm{~g} / \mathrm{h}$ por 48 horas después del bolo inicial, se realciona con una reducción en la dosis requerida de atropina, en la necesidad de intubación al ingreso, y en la duración del soporte ventilatorio $(37,38)$. Diferentes autores recomiendan reservar el uso de oximas para los pacientes con intoxicaciones moderadas a severas por organofosforados $(39,40)$. Dentro de sus efectos adversos se ha descrito hipertensión, náuseas, cefalea, taquicardia, larigoespasmo, hepatotoxicidad. La terapia temprana con oximas durante las primeras 24 horas de la intoxicación aguda por organofosforados, ha demostrado una disminución en la incidencia del síndrome intermedio y una recuperación más rápida de los efectos a nivel del sistema nervioso central (41-43).

Sulfato de magnesio: algunos estudios han mostrado que la administración de este medicamento a una dosis de $4 \mathrm{~g} /$ día, se relaciona con una disminución en el número de días de hospitalización y en la rata de mortalidad, cuando se instaura en forma temprana, sin que se haya encontrado relación con las dosis requeridas de atropina y oximas (44-46). También se ha empleado para el manejo de la hipertensión y algunos tipos de arritmias que se pueden presentar durante la intoxicación aguda por organofosforados.

\section{Manejo de complicaciones}

Si se presentan convulsiones la primera elección son las benzodiacepinas a dosis usuales. En caso de sindrome intermedio, se debe realizar intubación orotraqueal y traslado a UCI. Se debe realizar monitorización electrocardiográfica para el manejo específico de las arritmias. En el caso de intención suicida se recomienda la valoración por psiquiatría. La valoración del paciente a las 2-4 semanas después de haber sido dado de alta es importante para evaluar la presencia de signos de neuropatía retardada; para ello se requiere la confirmación mediante neuroconducciones y electromiografía y el inicio de rehabilitación $(47,48)$.

\section{Pronóstico}

La mortalidad en intoxicaciones agudas por organofosforados está entre el 3 y $20 \%$ (35). El pronóstico de estos pacientes depende del tipo de producto involucrado, la cantidad de plaguicida, la vía de absorción y la rapidez del diagnóstico y la instauración de las medidas terapéuticas (49). De igual forma es importante tener en cuenta la administración del tratamiento adecuado, pues la recuperación en los 2-4 primeros días es un indicativo de un buen pronóstico.

\section{Conclusiones}

Los cuadros de intoxicación con organofosforados constituyen un serio problema de salud pública en diversas partes del mundo (50) y nuestro país no es ajeno a esta realidad. Es importante conocer el tipo de compuestos que son usados en la población colombiana, la vía de ingreso del tóxico y el tiempo de evolución. El cuadro clínico de este tipo de intoxicación está conformado por un conjunto de signos y síntomas característicos que deben ser reconocidos por el médico en el servicio de urgencias, para poder brindar un manejo adecuado y oportuno al paciente. Los diferentes servicios de atención de emergencias así como las unidades de cuidado intensivo deben 
tener protocolos claros que permitan brindar el mejor manejo a estos pacientes para evitar complicaciones y/o secuelas. La prevención de las intoxicaciones es otro factor que se debe tener en cuenta, se puede lograr con educación sobre el manejo de estas sustancias y la promoción de uso de elementos de protección.

\section{Referencias}

1. Weselak M, Arbuckle T, Foster W. Pesticide Exposures and Developmental Outcomes: The Epidemiological Evidence. Journal of Toxicology and Environmental Healt. Part B. 2007; 10:41-80.

2. Vale J A. Toxicokinetic and Toxicodynamic Aspects of Organophosphorous Insecticide Poisoning. Toxicology Letters. 1998;102:649-52.

3. Eddleston M, Singh S, Bucley N. Organophosphorous Poisoning (Acute). Clinical Evidence. 2005;13:1744-55

4. Guidelines for Legislation on the Control of Pesticides. Food and Agriculture Organization of the United Nations. 1989 http://www.fao.org/AG/AGP/AGPP/Pesticid.

5. WHO. Public Health Impact of Pesticides Used in Agriculture. Ginebra: WHO 1990. http://www.who.int/heli/risks/toxics/ chemicals/en/index.html

6. Instituto Nacional de Salud Colombia- Subdirección de Vigilancia y Control. Intoxicación Aguda por Plaguicidas. Primer Semestre de 2007. http://www.ins.gov.co/index. php?idcategoria $=1470$

7. Instituto Nacional de Salud - Subdirección de Epidemiología y Laboratorio Nacional de Referencia- División Centros de Control de Enfermedades. Definiciones de Caso para los Eventos de Notificación Nacional. Sistema Nacional de Vigilancia en Salud Pública SIVIGILA. http://www.ins.gov. co/?idcategoria $=5579$

8. OPS. Situación Epidemiológica de las Intoxicaciones Agudas por Plaguicidas en el Istmo Centroamericano, 1992-2000. Boletín Epidemiológico 2002;23(3).

9. Reportes de vigilancia epidemiológica en Centroamérica. http://www.netsalud.sa.cr/ms/estadist/reportes/index.htm.

10. Lotti M. Cholinesterase Inhibition: Complexities in Interpretation. Clinical Chemistry. 1995;41:1814-8.

11. Eddleston M, Hillips M R. Self Poisoning with Pesticides. British Medical Journal. 2004;328:42-4.

12. Eldefrawi M E, Eldefrawi A T. Neurotransmitter Receptors as Targets of Pesticides. Journal of Environmental Science and Health. 1983;18:65-88.

13. Guyton A, Hall J. Textbook of Medical Physiology, Eleventh Edition 2006. 752

14. Dirección Seccional de Salud de Antioquia, Universidad de Antioquia. Guías de manejo de pacientes Intoxicados 2005.

15. Opawoye A D, Haque T. Insecticide/Organophsphorus Compound Poisoning in Children. Annals of Saudi Medicine. 1998; 18:171-2.

16. Bleecker J D, Neucker K, Colardyn F. Intermediate Syndrome in Organophosphorus Poisoning: A Prospective Study. Critical Care Medicine. 1993;21(11):1706-1711.

17. Salvi R, Lara D, Ghisolfi E, Portela L, Dias R, Souza D. Neuropsychiatric Evaluation in Subjects Chronically Exponed to Organophosphate Pesticides. Toxicological Sciences. 2003; 72:267-271

18. Weiss B, Amler S H, Amler R. Pesticides. Pediatrics. 2004;113(4):1030-1036.
19. Worek F, Mast U, Kiderlen E, Diepold C, Eyer P. Improved Determination of Acetylcholinesterase Activity in Human Whole Blood. Clinica Chimica Acta. 1999;288:73-90.

20. Reiner E, Buntic A, Trdak M, Simeon V. Effect of Temperature on the Activity of Human Blood Cholinesterases. Archives of Toxicology. 1974;32:347-50.

21. Aprea C, Colosio C, Mammone T, Mimosa C, Maroni M. Biological Monitoring of Pesticide Exposure: A Review of Analytical Methods. Journal of Chromatography B. 2002;769:191219.

22. Nouira, Abroug, Elatrous. Prognostic Value of Serum Cholinesterase in Organophosphate Poisoning. CHEST. 1994;106(6):1811-14.

23. Baer A, Kirk M, Holstege C. Organophosphates, Carbamates, Pesticides and Herbicides. In: Erickson T, Ahrens W, Ask S, Baum C, Ling L. Pediatric Toxicoloogy. Diagnosis \& Management of the Poisoned Child. 1rt. Edition. Editorial McGrawHill. New York; 2005: 352-356.

24. Maroni M. Organophosphorous Pesticides. Toxicology. 2000;142:9-37.

25. Fillmore C, Messenger J. A Cholinesterase Testing Program for Pesticide Applicators. Journal Occupational of Medicine. 1993;35(1):61-70.

26. Eddleston M, Dawson A, Karalliedde L. Early Management after Self Poisoning with an Organophosphorous or Carbamate Pesticide: A Treatment Protocol for Junior Doctors. Critical Care. 2004;8:391-7.

27. American Academy of Clinical Toxicology, European Associations of Poison Centres and Clinical Toxicologist. Position Statement. Journal of Toxicology- Clinical Toxicology. 1997;35:753-62.

28. Hoffman R S, Goldfrank L R. The Poisoned Patient with Altered Consiusness. Journal of the American Medical Association. 1995;274:562-69.

29. Bateman D N. Gastric Decontamination- A View for the Millenium. Journal Accident and Emergency Medicine. 1999;16:84-6.

30. Gutmann L, Besser R. Organophosphate Intoxication: Pharmacologic, Neurophysiologic, Clinical, and Therapeutic Considerations. Seminars in Neurology. 1990;10:46-51.

31. Sungur M, Guven M. Intensive Care Management of Organophosphate Insecticide Poisoning. Critical Care. 2001;5;211-15.

32. Geller R J, Singleton K L, Tarantino M L. Nosocomial Poisoning Associated with Emergency Department Treatment of Organophosphate Toxicity-Georgia 2000. Journal of Toxicology- Clinical Toxicology. 2001;39:333-36.

33. Heard K. Gastrointestinal Decontamination. Medical Clinics of North America. 2005;89:1067-78.

34. Jokanovic M, Stojiljkovic M. Current Understanding of the Application of Pyridinium Oximes as Cholinesterase Reactivators in Treatment of Organophosphate Poisoning. European Journal of Pharmacology. 2006;553:10-17.

35. Hernandez J. Intoxicación por Plaguicidas y Organofosforados. En: Guias de Práctica Clínica: Toxicología, Hospital Universitario San Ignacio 2004;2:84-91.

36. Pope C, Karanth S, Liu J. Pharmacology and Toxicology of Cholinesterase Inhibitors: Uses and Misuses of a Common Mechanism of Action. Environmental Toxicology and Pharmacology. 2005;19:433-446.

37. Pawar K, Bhoite R, Pillay C, Chavan S, Malshikare D, Garad S. Continuous Pralidoxime Infusion versus Repeated Bolus Injection to treat Organophosphorus Pesticide Poisoning: A Randomised Controlled Trial. Lancet. 2006;368:2136-41. 


\section{INTOXICACIÓN POR ORGANOFOSFORADOS}

38. Eddleston M, Mohamed F, Davies J, Eyer P, Worek F, Sheriff M, Buckley N. Respiratory Failure in Acute Organophosphorus Pesticide Self-poisoning. Q J Med. 2006;99:513-522.

39. Roberts D, Aaron C. Management of Acute Organophosphorus Pesticide Poisoning. British Medical Journal. 2007;334:629-634.

40. Jalali N, Pajoumand A, Abdollahi M, Shadnia Sh, Pakravan N. Pesticides Poisoning: One-year Report of LoghmanHakim Hospital Poison Center. Medical Reseacrh Program. 2003;1:1-9.

41. Al Khod, Muscat, Oman. Potential Therapeutic Agents in the Management of Organophosphorus Poisoning. Critical Care. 2002;6(3):260-261.

42. Eddleston M, Darren Roberts D, Buckley N. Management of Severe Organophosphorus Pesticide Poisoning. Critical Care. 2002;6:259.

43. Miller M A. Organophosphorus and Carbamate Insecticides. In: Olson K. Poisson \& Drug Overdose. 4th edition. McGrawHill. New York; 2004: 291-295.

44. Pajoumand A, Shadnia Sh, Rezaie A, Abdi M, Abdollahi M. Benefits of Magnesium Sulfate in the Management of Acute Human Poisoning by Organophosphorus Insecticidas. Human \& Experimental Toxicology. 2004;23:565-569.
45. Petroianu G, Ruefer R. Beta-blockade or Magnesium in Organophosphorus Insecticide Poisoning. Anaesthesia and Intensive Care. 1992;20:538-9.

46. Singh H, Avasthi G, Khurana D, Whig J, Mahajan R. Neurophysiological Monitoring of Pharmacological Manipulation in Acute Organophosphate Poisoning. The Effects of Pralidoxime, Magnesium Sulphate and Pancuronium. Electroencephalography and Clinical Neurophysiology. 1998;107:140-8.

47. Johnson M K, Vale J A. Clinical Management of Acute Organophsphorus Insecticide Poisoning: An Overview. En Ballantyne B, Marrs T, eds. Clinical and Experimental Toxicology of Organophosphates and Carbamates. Oxford: Butterworth Heinemann. 1992:528-35.

48. Eddleston M, Bateman N. Pesticides. Medicine 2007;35(12): 646-648.

49. Ministerio de la Protección Social. Guía de Atención Integral en Salud Ocupacional Basada en la Evidencia para Trabajadores Expuestos a Plaguicidas Inhibidores de la Colinesterasa (organofosforados y Carbamatos) GATISO PIC 2007.

50. Jeyaratnama J. Acute Pesticide Poisoning: A Major Global Health Problem. World Health Statistic Quarterly. 1990;43:139-44. 